\title{
Gender differences in the use of primary prevention ICDs in New Zealand patients with heart failure
}

\author{
Khang-Li Looi, ${ }^{1}$ Karishma Sidhu, ${ }^{1}$ Lisa Cooper, ${ }^{1}$ Liane Dawson, ${ }^{2}$ Debbie Slipper, ${ }^{2}$ \\ Andrew Gavin, ${ }^{2}$ Nigel Lever ${ }^{1}$
}

${ }^{1}$ Green Lane Cardiovascular Service, Auckland City Hospital, Auckland, New Zealand ${ }^{2}$ Cardiovascular Division, North Shore Hospital, Auckland, New Zealand

Correspondence to Dr Khang-Li Looi, Green Lane Cardiovascular Service, Auckland City Hospital, Auckland, 1023, New Zealand; khanglil@adhb. govt.nz

Received 28 November 2017 Revised 27 December 2017 Accepted 27 December 2017 Published Online First 13 January 2018

CrossMark

To cite: Looi K-L, Sidhu K, Cooper L, et al. Heart Asia 2018;10:1-6. doi:10.1136/ heartasia-2017-010985

\section{ABSTRACT}

Objective Women have been under-represented in randomised clinical trials for primary prevention implantable cardioverter defibrillators (ICDs), and there are concerns about the efficacy of devices between genders. Our study aimed to investigate gender differences in the use of primary prevention ICD in patients with heart failure from the northern region of New Zealand.

Methods Patients with heart failure with systolic dysfunction who received primary prevention ICD/cardiac resynchronisation therapy-defibrillator (CRT-D) in the northern region of New Zealand from 1 January 2007 to 1 June 2015 were included. Complications, mortality and hospitalisation events were reviewed.

Results Of the 385 patients with heart failure implanted with ICD/CRT-D, women comprised 15.1\% $(n=58)$, and no change in utilisation of these devices was observed over the study period among women. Women were more likely to have non-ischaemic cardiomyopathy and have higher perioperative complications ( $8.6 \%$ vs $2.5 \%, \mathrm{P}=0.02$ ), with non-significant higher trend towards increased lead displacement $(5.2 \%$ vs $1.8 \%$, $\mathrm{P}=0.12)$. Women appeared to have lower all-cause (10.3\% vs $18.7 \%, P=0.12)$, cardiovascular ( $5.2 \%$ vs $11.9 \%, P=0.13)$ and heart failure (3.5\% vs $7.9 \%$, $\mathrm{P}=0.22$ ) mortalities but was not statistically significant. There were no gender differences in all-cause $(70.7 \%$ vs $67 \%, P=0.58)$ or heart failure (19\% vs $25 \%, P=0.32$ ) readmissions.

Conclusion Perioperative complications were significantly more common in women referred for ICD/ CRT-D. Although there has been a significant increase in ICD implantation rates, gender differences in the use of these devices still exist in New Zealand, in keeping with the demographics of ischaemic heart disease and systolic dysfunction between genders.

\section{INTRODUCTION}

Clinical trials on the use of implantable cardioverter defibrillators (ICDs) and cardiac resynchronisation therapy (CRT) have demonstrated overall survival benefits in selected patients with heart failure (HF). ${ }^{1-5}$ ICDs reduce the risk of sudden cardiac death (SCD), whereas the mortality benefit of CRT is related, in part, to favourable left ventricular reverse remodelling with attenuation of both $\mathrm{HF}$ death as well as SCD.

The role of primary prevention ICD in women with HF has not been well established. Many of the clinical trials of ICDs were underpowered to assess risks and benefits of ICDs in women. Traditionally women have been under-represented in trials of HF and ICD therapy, with only small numbers of women being enrolled. ${ }^{167}$ According to current international guidelines, recommendations for primary prevention ICD/CRT-D are not different for men and women with HF and impaired left ventricular function. A meta-analysis of the five primary prevention trials (Multicenter Unsustained Tachycardia Trial [MUSTT], Multicenter Automatic Defibrillator Implantation Trial II [MADIT II], Defibrillator in Acute Myocardial Infarction Trial [DINAMIT], Defibrillators in Non-Ischemic Cardiomyopathy Treatment Evaluation [DEFINITE], and Sudden Death in Heart Failure Trial [SCD-HeFT]) showed that men, but not women, derived a survival benefit from ICD as compared with antiarrhythmic drugs. ${ }^{8}$ However, a recent primary prevention trial in patients with HF confirmed equal survival advantage in both men (HR $0.76,95 \%$ CI 0.67 to $0.87, \mathrm{P}<0.001$ ) and women (HR $0.78,95 \% \mathrm{CI} 0.66$ to $0.92, \mathrm{P}=0.003$ ). ${ }^{9}$ These findings support the use of primary prevention ICD in eligible patients regardless of gender.

Despite women accounting for 50\% of HF admissions, eligible women were less likely to receive an ICD compared with men (40\% lower odds).$^{10}$ In New Zealand, a gender difference in ICD implantation was documented by Larsen et al ${ }^{11}$ during the period of 2000-2007. The study showed the majority $(71 \%)$ of the primary prevention ICDs being implanted were in men. ${ }^{11}$ Currently there are no data on the use of primary prevention ICD for women with HF in New Zealand. Our study aimed to examine the gender differences in the use of primary prevention ICDs in patients with HF in the northern region of New Zealand.

\section{METHODS}

This was an observational study that included patients with HF who received primary prevention ICD/CRT-D in the northern region of New Zealand. The northern region of New Zealand is defined as the four northernmost district health boards (DHBs) areas and consists of Auckland DHB, counties Manukau DHB, Northland DHB and Waitemata DHB. The four DHBs in the northern region serve $38 \%$ of the total New Zealand population, with an estimated 1.76 million people in this region. ${ }^{12}$ The study period was from January 2007 to 1 June 2015. We included patients undergoing all de novo ICD and CRT-D implants, all pacemaker upgrades to ICD and CRT-D, and epicardial lead placement with CRT-D. Procedures involving solely ICD and CRT-D pulse generator replacement were excluded. 
Patient demographic data, procedure-related data, acute (within 24 hours of implant), early (>24 hours to 2 weeks from implant) and late ( $\geq 2$ weeks after device implantation) complications were obtained via review of pacing database and clinical records held on electronic clinical record information system.

Mortality data were collected using New Zealand mortality collection and National Minimum Datasets (NMDS) inpatient hospitalisation data. These include all registered deaths rather than just deaths in the hospital. The cause of death data were available up until the end of 2013. For those with no cause of death data from NMDS, review of clinical records was performed to further determine the cause of death.

Hospitalisation events were identified using the administrative data of the Ministry of Health and NMDS inpatient hospitalisation data via National Health Index (NHI) linkage up to December 2015. The NHI number is a unique identifier that is assigned to every person who uses health and disability support services in New Zealand. HF hospitalisation was defined using the International Classification of Diseases-10 diagnosis codes (I110, I130, I132, I500, I501 and I509).

\section{Statistical analysis}

Baseline demographics were summarised as means with $1 \mathrm{SD}$ or frequencies with percentage (\%). Comparisons of baseline characteristics between genders were conducted with either the Wilcoxon rank-sum test, the $\chi^{2}$ test or the two-sample $\mathrm{Z}$ test. Plots to depict the implantation frequency of ICD and CRTD among men and women over the course of the study were constructed. Kaplan-Meier survival curves were generated to depict the distribution of cardiovascular and HF mortalities over time. The difference of the survival distributions between men and women was evaluated with the log-rank test.

The difference in complication rates, device therapy treatment rates and mortality rates between genders was assessed with the $\chi^{2}$ test or the two-sample $Z$ test. Readmission rates between genders were compared with the two-sample $\mathrm{Z}$ test. Logistic regression was used to determine predictors of all-cause mortality and HF mortality after adjusting for baseline characteristics.

Statistical analyses were performed using the statistical package SAS V.9.3. All $P$ values resulted from two-sided tests and a $P$ value of $<0.05$ was considered statistically significant.

\section{RESULTS}

From January 2007 to June 2015, a total of 385 patients with HF underwent 404 procedures. Women comprised 15.1\% $(n=58)$ of the study cohort. Throughout the study period, there were differences in ICD/CRT-D utilisation in men and women. In men, there was a steady increase in ICD/CRT-D utilisation, but this trend of increase was not seen in women (figure 1A,B).

Differences in baseline characteristics were summarised in table 1 . Women were more likely to have non-ischaemic cardiomyopathy (NICM) and cardiac sarcoidosis than men. In addition, women had a higher prevalence of left bundle branch block (LBBB) (43.1\% vs 32.4\%) but were less likely to have chronic atrial fibrillation (AF). No significant differences were found in age, mean left ventricular ejection fraction (LVEF), New York Heart Association functional classes or other comorbidities.

\section{Complications}

During the 24 hours immediately after device implantation, acute perioperative complications were more common in women compared with men $(8.6 \%$ vs $2.1 \%, \mathrm{P}=0.008)$ (figure 2$)$. In particular, women had a non-significant higher trend of lead displacement $(5.2 \%$ vs $1.8 \%, \mathrm{P}=0.12)$ and cardiac tamponade requiring interventions $(0.18 \%$ vs 0$)$ when compared with men.

No significant differences were observed in early and late complications between men and women (figure 2).

\section{Device therapy}

Overall $19.7 \%$ of patients received antitachycardia pacing (ATP) and $17.1 \%$ had appropriate ICD shocks for ventricular tachyarrhythmias. There was no gender difference in the need for appropriate ATP (13.8\% in women vs $20.8 \%, \mathrm{P}=0.22)$ or shocks (12.1\% in women vs $18 \%, \mathrm{P}=0.27)$. There was no gender difference in the time to first ATP $(3.6 \pm 2.6$ years vs $3.61 \pm 2.3$ years, $\mathrm{P}=0.89$ ) or time to first appropriate ICD shocks (3.7 \pm 2.6 years vs $3.6 \pm 2.2$ years, $\mathrm{P}=0.77$ )

At the end of the follow-up, 9.1\% of patients had received inappropriate shocks, but no gender difference was noted $(8.6 \%$ vs $9.2 \%, \mathrm{P}=0.89$ ).
A

\section{ICD Utilisation By Gender From Year 2007-Mid 2015}

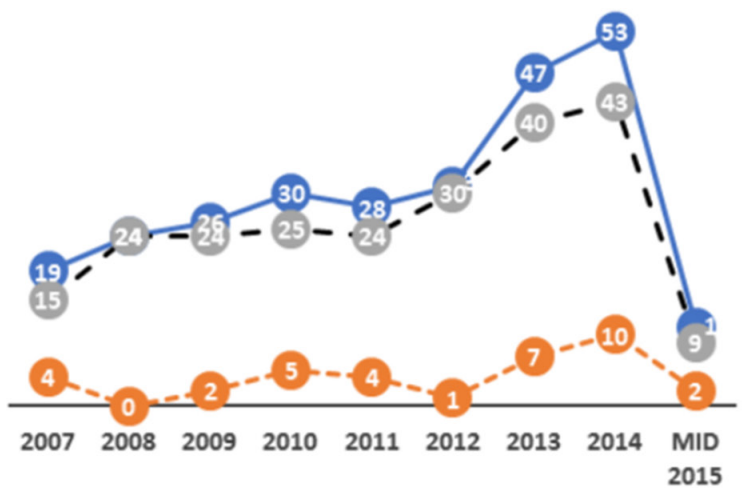

B

\section{CRT-D Utilisation By Gender From Year 2007-Mid 2015}

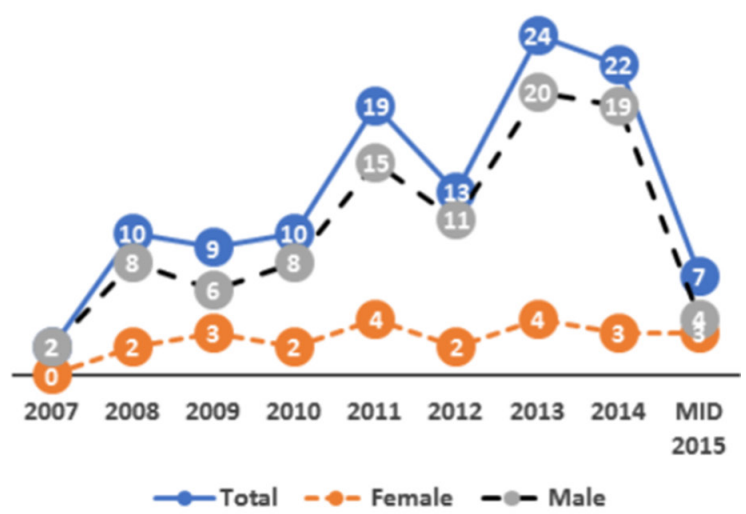

Figure 1 (A) Overall implantable cardioverter defibrillator (ICD) utilisation in men and women over the study period. (B) Overall cardiac resynchronisation therapy-defibrillator (CRT-D) utilisation in men and women over the study period. 
Table 1 Baseline characteristics of women and men with primary prevention ICD

\begin{tabular}{|c|c|c|c|}
\hline & Women $(n=58)$ & Men $(n=327)$ & $\mathbf{P}$ \\
\hline Mean age (years $\pm S D)$ & $58.2 \pm 12.3$ & $59.2 \pm 11.3$ & 0.68 \\
\hline \multicolumn{4}{|l|}{ Ethnicity (\%) } \\
\hline New Zealand European & $40(69.0)$ & $197(60.2)$ & 0.19 \\
\hline Maori & $11(18.9)$ & $43(13.2)$ & \\
\hline Pacific Island & $4(6.9)$ & $40(12.2)$ & \\
\hline Asian & $3(5.2)$ & $41(12.6)$ & \\
\hline Unspecified & 0 & $6(1.8)$ & \\
\hline Height (m) & $1.63 \pm 0.07$ & $1.75 \pm 0.07$ & $<0.001$ \\
\hline Weight (kg) & $79.3 \pm 17.9$ & $88.7 \pm 17.3$ & 0.0012 \\
\hline Body mass index $\left(\mathrm{m} / \mathrm{kg}^{2}\right)$ & $29.9 \pm 6.3$ & $28.9 \pm 5.3$ & 0.29 \\
\hline \multicolumn{4}{|l|}{ DHBs $(\%)$} \\
\hline Auckland DHB & $16(27.6)$ & $73(22.3)$ & 0.82 \\
\hline Counties Manukau DHB & $16(27.6)$ & $92(28.1)$ & \\
\hline Northland DHB & $4(6.9)$ & $29(8.9)$ & \\
\hline Waitemata DHB & $22(37.9)$ & $133(40.7)$ & \\
\hline \multicolumn{4}{|l|}{ Underlying aetiology } \\
\hline Ischaemic cardiomyopathy & $9(15.5)$ & $149(45.6)$ & $<0.0001$ \\
\hline Non-ischaemic cardiomyopathy & $37(63.8)$ & $155(47.4)$ & 0.0213 \\
\hline Valvular heart disease & $2(3.5)$ & $5(1.5)$ & 0.3134 \\
\hline Cardiac sarcoidosis & $4(6.9)$ & $1(0.3)$ & $<0.0001$ \\
\hline Others & $4(6.9)$ & $17(5.2)$ & 0.6 \\
\hline \multicolumn{4}{|l|}{ Type of devices } \\
\hline ICD & $35(60.3)$ & $234(71.6)$ & 0.08 \\
\hline Single-chamber ICD & $29(50.0)$ & $176(53.8)$ & \\
\hline CRT-D & $23(39.7)$ & $93(28.4)$ & \\
\hline \multicolumn{4}{|l|}{ NYHA class } \\
\hline I & $11(19)$ & $93(28.4)$ & 0.31 \\
\hline II & $35(60.3)$ & $169(51.7)$ & \\
\hline III & $12(20.7)$ & 65 (19.9) & \\
\hline Mean LVEF (\%) & $24.2 \pm 5.0$ & $24.4 \pm 5.4$ & 0.48 \\
\hline \multicolumn{4}{|l|}{ Atrial arrhythmias } \\
\hline Paroxysmal AF & $6(10.3)$ & $32(9.8)$ & 0.89 \\
\hline Chronic AF & $3(5.2)$ & 65 (19.9) & 0.0068 \\
\hline AV node ablation & $1(1.7)$ & $1(0.3)$ & 0.28 \\
\hline Diabetes mellitus & $12(20.7)$ & $72(22.1)$ & 0.81 \\
\hline Hypertension & $15(25.9)$ & $94(28.8)$ & 0.64 \\
\hline \multicolumn{4}{|l|}{ QRS morphological type } \\
\hline RBBB & $1(1.7)$ & $27(8.3)$ & 0.07 \\
\hline LBBB & $25(43.1)$ & $106(32.4)$ & \\
\hline IVCD & $4(6.9)$ & $19(5.8)$ & \\
\hline Paced & $4(6.9)$ & $9(2.8)$ & \\
\hline Mean QRS duration (ms) & $140.2 \pm 35$ & $137.2 \pm 35.4$ & 0.68 \\
\hline \multicolumn{4}{|l|}{ Estimated glomerular filtration rate } \\
\hline Mean & $60 \pm 15.2$ & $63.4 \pm 14.9$ & 0.13 \\
\hline
\end{tabular}

$A F$, atrial fibrillation; $A V$, atrio-ventricular; $C R T-D$, cardiac resynchronisation therapydefibrillator; DHB, district health board; ICD, implantable cardioverter defibrillator; IVCD, intraventricular conduction delay; LBBB, left bundle branch block; LVEF, left ventricular ejection fraction; NYHA, New York Heart Association; RBBB, right bundle branch block.

\section{Mortality}

The total duration of follow-up was 10.2 years with a mean duration of $3.64 \pm 2.17$ years. At the end of the follow-up, a total of $67(17.4 \%)$ patients had died: $61(18.7 \%)$ men and $6(10.3 \%)$ women $(\mathrm{P}=0.12)$. Women appeared to have lower cardiovascular mortality $(5.2 \%$ vs $11.9 \%, \mathrm{P}=0.13)$ and $\mathrm{HF}$ mortality $(3.5 \%$ vs $7.9 \%, \mathrm{P}=0.22$ ) compared with men but was not statistically significant. There were only two sudden arrhythmic deaths and
Acute, Early and Late Complications in Men and Women

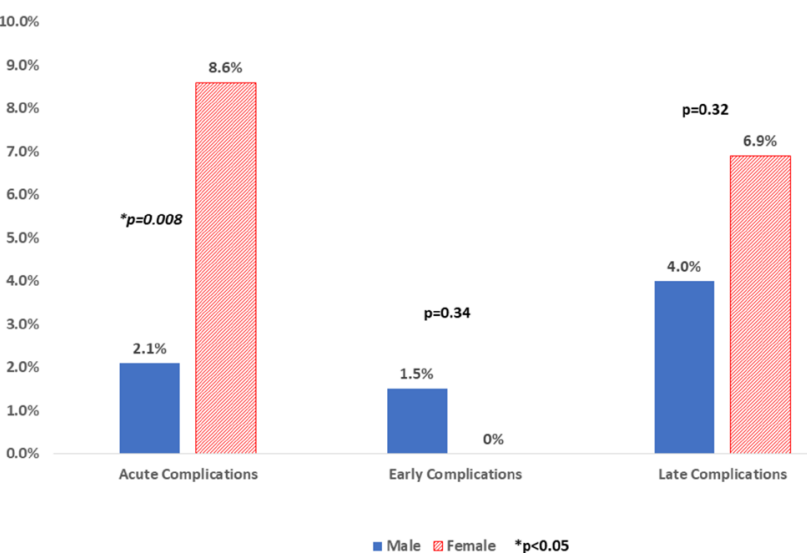

Figure 2 Acute, early and late complications by gender.

both were men. Figure 3A,B showed the Kaplan-Meier survival curve for cardiovascular and HF mortalities in women and men.

After adjusting for baseline differences including gender, low LVEF (OR $0.94,95 \%$ CI 0.892 to $0.99, \mathrm{P}=0.02$ ) was the only predictor of all-cause mortality, whereas CRT-D use was associated with improved all-cause survival (OR 0.419, 95\% CI 0.183 to $0.962, \mathrm{P}=0.04)$. No predictors were of statistical significance in HF mortality.

\section{All-cause and HF readmissions}

During follow-up, there were 1194 all-cause hospital readmissions in 260 patients, which include 275 (23\%) HF admissions. All-cause readmissions occurred in $70.7 \%$ of women compared with $67 \%$ of men $(\mathrm{P}=0.58)$. HF admissions occurred in $19 \%$ of women compared with $25 \%$ of men $(\mathrm{P}=0.32)$.

\section{DISCUSSION}

We examined the gender differences in the use of primary prevention ICD/CRT-D in real-world HF population in the northern region of New Zealand. The following are the main findings: (1) Women comprised only $15.1 \%$ of those who received primary prevention ICD/CRT-D. (2) In women undergoing implantation, there was a higher prevalence of NICM, LBBB with broader complex width and a lower prevalence of AF. (3) Women have overall higher periprocedural complication rates but similar early and late complication rates. (4) No gender differences were noted in rates of appropriate and inappropriate ICD shocks. (5) No gender differences were noted in all-cause and HF rehospitalisation rates and mortality.

Epidemiological and clinical studies have suggested gender-related differences in the delivery of guideline-recommended HF treatments. ${ }^{13} 14$ In the Get With the Guidelines-Heart Failure programme, a significant increase in ICD use was observed over time in patients with history of HF and LVEF ( $\leq 35 \%)$, but gender differences persisted. ${ }^{15}$ A study by Hernandez et $a l^{16}$ showed that while $44 \%$ of eligible men with HF and LVEF $\leq 30 \%$ received ICD, only $28 \%$ of eligible women received ICD therapy. New Zealand traditionally has had lower implant rates/million population for ICD. ${ }^{11}$ Taking into account affordability and capacity constraints, the published $2010 \mathrm{New}$ Zealand guidelines are relatively conservative (box 1 ) and this may result in low referral rates. ${ }^{17}$ In our study, the percentage of ICD/CRT-D utilisation in men gradually increased from year 2007 to mid-2015, but this is not seen in women and a gender discrepancy remained in the use of these complex devices (figure $1 \mathrm{~A}, \mathrm{~B}$ ). The original trials of 

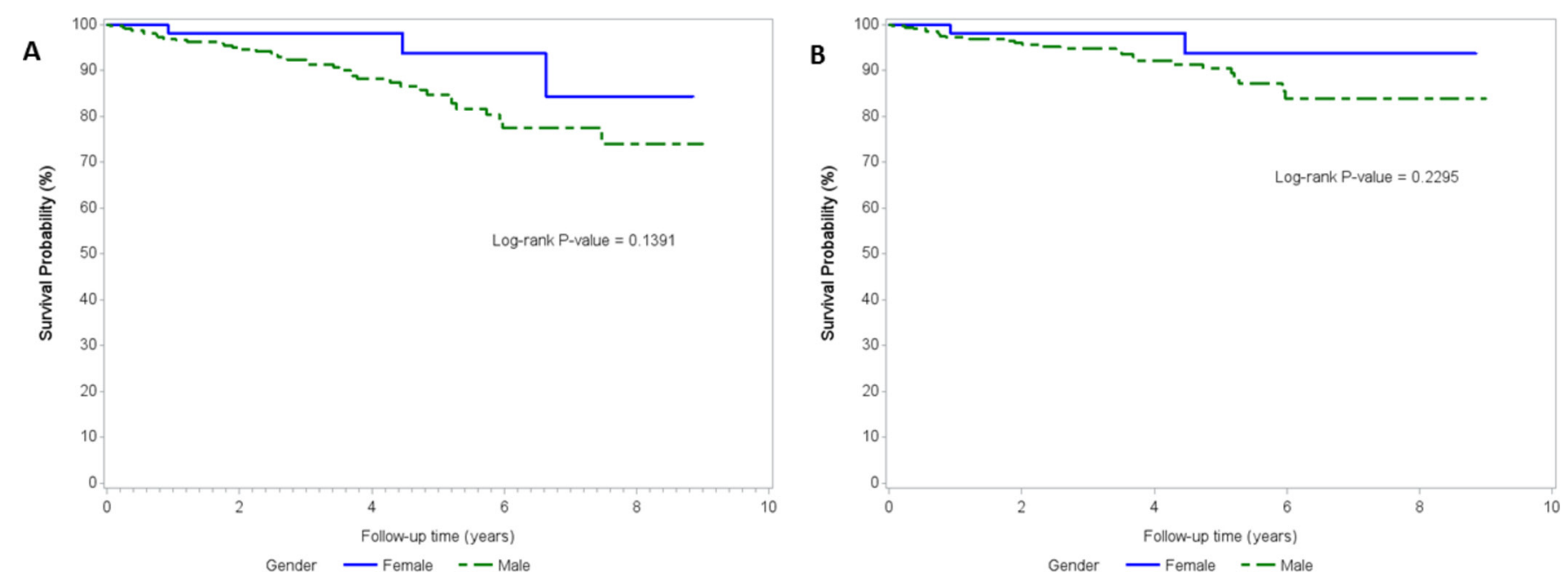

Figure 3 (A) Kaplan-Meier survival curve for cardiovascular mortality. (B) Kaplan-Meier survival curve for heart failure mortalities.

ICD/CRT-D showed the benefit derived from ICD is greater in patients with ischaemic cardiomyopathy, which is more common in men and occurs at a younger age. ${ }^{137}$ Women are more likely to have HF with preserved systolic function and present at a later

Box 1 New Zealand primary implantable cardioverter defibrillator implantation and cardiac resynchronisation therapy guidelines ${ }^{17}$

\section{Recommendations for primary ICD implantation in New} Zealand

- Patients with ICM at least 1 month after acute MI or an NICM present for at least 3 months.

- $\mathrm{EF} \leq 30 \%$ measured $\geq 3$ months after optimal heart failure treatment.

- NYHA class II or III.

- On maximal heart failure medications, including ACE inhibitors or angiotensin receptor blockers, beta-blockers and spironolactone as tolerated for at least 3 and preferably 6 months.

- No clinical symptoms or findings that would make them a candidate for a revascularisation procedure.

- At least 3 months remote from any revascularisation procedure.

- No associated disease with a likelihood of survival $<18$ months.

- Age $\leq 75$ years.

Recommendations for cardiac resynchronisation therapy in New Zealand

- $\mathrm{EF} \leq 35 \%$ after $\geq 6$ weeks of optimal heart failure treatment, with QRS duration $>149$ ms or 120-149 ms with two additional criteria for dyssynchrony (aortic pre-ejection delay $>140 \mathrm{~ms}$, interventricular mechanical delay $>40 \mathrm{~ms}$ or delayed activation of the posterolateral left ventricular wall).

- NYHA class III.

- No major cardiovascular event in the prior 6 weeks and be in sinus rhythm.

- No major comorbidity reducing survival $<18$ months or seriously impairing quality of life.

$E F$, ejection fraction; ICD, implantable cardioverter defibrillator; ICM, ischaemic cardiomyopathy; MI, myocardial infarction; NICM, nonischaemic cardiomyopathy; NYHA, New York Heart Association. age. ${ }^{18}$ Similarly, we have observed women with different clinical profiles compared with men (table 1), which may account for the lower ICD/CRT-D implant rates in women. The mean age of women who received these devices was younger because of our more restrictive recommendations, otherwise they shared similar baseline characteristics to other published data. ${ }^{171920}$

MacFadden et $a l^{20}$ reported a 50\% higher occurrence of any major or minor complications in women at 45-day follow-up. Similarly, recent findings from the National Cardiovascular Data Registry (NCDR) demonstrated a higher risk of cardiac perforation and pneumothorax in women. ${ }^{19}$ In our current study, women had higher perioperative complication rates than men, but there were no gender differences in the longer term device-related complications. This differs from the previously described increased risk of complications in women in general. This may be explained by the small number of women included in the study, and therefore no conclusive evidence of gender differences in late complications could be drawn.

Some studies have shown that women receiving primary prevention ICDs have a lower risk of death and appropriate ICD shocks than men. In a large multicentre French registry, women who had ICD implantation for primary prevention had a significantly lower likelihood of receiving appropriate ICD therapies $(17.4 \%$ vs $23 \%, \mathrm{P}<0.001)$ but had similar mortality compared with men $(\mathrm{HR}=0.87,95 \% \mathrm{CI} 0.66$ to $1.15, \mathrm{P}=0.324) .{ }^{21}$ There was no gender difference observed with inappropriate shocks $(6.7 \%$ vs $6.7 \%$, OR $1.0,95 \%$ CI 0.74 to $1.35, \mathrm{P}=0.997) .^{21}$ Similarly, Seegers et $^{2} \mathrm{l}^{22}$ showed that women received 50\% less appropriate ICD shocks than men $(3.6 \%$ vs $6.3 \%$ per year, $\mathrm{P}=0.002)$, although both groups have similar mortality $(\mathrm{P}=0.08)$. In a recent systematic review and meta-analysis, women were found to have a lower incidence of first appropriate ICD shocks and death than men but a similar risk of receiving inappropriate ICD shocks. ${ }^{23}$ Contrary to the published studies, our study showed that there was no gender difference in the appropriate and inappropriate ICD shocks. There appeared to be a trend towards lower all-cause, cardiovascular and HF mortalities in women, but it was not statistically significant. This may be explained by the small number of women, and our results would be consistent with the literature with lower mortalities observed in women.

There has been increasing interest in the optimisation of ICD programming to prevent inappropriate and appropriate but unnecessary device therapy. Prior to 2013, our ICD programming was not standardised and often comprised manufacturer 
defaults, which were tailored to each patient by depending on history, results of defibrillation threshold testing and the electrophysiologists' preferences. Three different trials demonstrated recently that a longer number of intervals to detect ventricular fibrillation (NID) and a high rate cut-off reduce ICD therapies in primary prevention patients. ${ }^{24-26}$ Subsequent to these publications, we have moved to a programming strategy of longer NID in line with the published expert consensus statement on optimal ICD programming and testing. ${ }^{27}$

$\mathrm{HF}$ is a chronic, long-term health condition, but improved survival has brought with it significant financial burdens on our healthcare system. In New Zealand, approximately 5500 patients are hospitalised with decompensated HF each year. ${ }^{28}$ Poor outcomes are common after hospitalisation for HF, with 1 -year readmission rates $>50 \%$ and 1 -year mortality $>30 \%{ }^{29}$ Findings from the NCDR showed that women had higher HF readmission rates than did men $(14 \%$ vs $10 \%, \mathrm{P}<0.001) .{ }^{19}$ Even all-cause readmissions within 6 months were higher in women than in men, and these differences persisted after adjusting for baseline differences (OR 1.22, 95\% CI 1.16 to $1.28, \mathrm{P}<0.001) .{ }^{19}$ However, in our study there were no gender differences in all-cause hospitalisation rates including HF hospitalisation rates. It is possible that the small number of women included in our study could not account for differences. It is also possible that higher CRT use in women in our population (39.7\%) potentially contributed to the comparable HF hospitalisation rates. A recent meta-analysis revealed that women derived greater benefit from CRT than men. ${ }^{30}$ However, additional studies with a larger number of women are needed to determine if there are other unmeasured confounders that might contribute to gender differences and outcomes in our population.

\section{Limitations}

First, our study lacks the denominator describing women with HF who were eligible but not implanted to demonstrate a real

\section{Key messages}

\section{What is already known about this subject?}

- Many of the clinical trials of implantable cardioverter defibrillators (ICDs) were underpowered to assess the impact of primary prevention ICDs for women.

\section{What does this study add?}

- ICD implantation was less common in women in New Zealand, likely in keeping with the demographics of ischaemic heart disease and heart failure with preserved systolic function.

- Perioperative complications were more common in women referred for primary prevention ICDs.

- Women appeared to have lower long-term all-cause, cardiovascular and heart failure mortalities, although not statistically significant.

\section{How might this impact on clinical practice?}

- This study shows that despite the higher perioperative complications in women who received primary prevention ICDs, they appeared to have lower long-term mortality compared with men.

- This study highlights the importance of ongoing genderspecific analysis in medical device clinical studies to further improve the application of available evidence on ICDs in appropriate eligible women with heart failure. disparity in the use of these complex devices. Second, our study is limited by the small number and sample size of women included, which in itself may not be powered enough to detect differences in the outcome. Third, our study was a non-randomised observational study from four DHBs; therefore, our results may not apply to other centres in New Zealand. However, given the paucity of data of these devices in New Zealand, our study represents the real-world data on the use of these devices in HF women and their outcomes.

\section{CONCLUSION}

In our study, the incidence of early complications was higher in women referred for primary prevention ICD/CRT-D. Women also presented with a different clinical profile from men and account for a minority of ICD/CRT-D recipients. The differences in disease pattern and left ventricular impairment between genders may have contributed to our results. Although these results should not preclude eligible women from receiving these devices, a broader perspective on outcomes such as cost and quality of life is needed to inform decisions around primary ICD implantation in women with HF.

Acknowledgements The authors thank Charlene Nell, Desktop Support Team Administrator at Green Lane Cardiovascular Services/Cardiology Department, for her secretarial support.

Contributors KLL was involved in conception and design of the study. KLL, LC, LD and DS were involved in data collection. KLL and KS were involved in analysis and interpretation of data. KLL, KS, LC, AG and NL contributed to the writing of the manuscript as well as jointly developing the structure and arguments for the paper. All authors reviewed and approved the final manuscript.

Competing interests None declared.

Patient consent Obtained.

Ethics approval Ethics approval for the study was obtained from the Central Health and Disability Ethics Committee (ethics ref: 15/CEN/58/AM02).

Provenance and peer review Not commissioned; externally peer reviewed.

(c) Article author(s) (or their employer(s) unless otherwise stated in the text of the article) 2018. All rights reserved. No commercial use is permitted unless otherwise expressly granted.

\section{REFERENCES}

1 Bardy GH, Lee KL, Mark DB, et al. Amiodarone or an implantable cardioverterdefibrillator for congestive heart failure. N Engl J Med 2005;352:225-37.

2 Kadish A, Dyer A, Daubert JP, et al. Prophylactic defibrillator implantation in patients with nonischemic dilated cardiomyopathy. N Eng/ J Med 2004;350:2151-8.

3 Moss AJ, Zareba W, Hall WJ, et al. Prophylactic implantation of a defibrillator in patients with myocardial infarction and reduced ejection fraction. N Eng/ J Med 2002;346:877-83.

4 Bristow MR, Saxon LA, Boehmer J, et al. Cardiac-resynchronization therapy with or without an implantable defibrillator in advanced chronic heart failure. $N$ Engl J Med 2004;350:2140-50.

5 Cleland JG, Daubert JC, Erdmann E, et al. The effect of cardiac resynchronization on morbidity and mortality in heart failure. N Eng/ J Med 2005;352:1539-49.

6 Buxton AE, Lee KL, DiCarlo L, et al. Electrophysiologic testing to identify patients with coronary artery disease who are at risk for sudden death. N Eng/ J Med Overseas Ed 2000;342:1937-45.

7 Moss AJ, Hall WJ, Cannom DS, et al. Improved survival with an implanted defibrillator in patients with coronary disease at high risk for ventricular arrhythmia. N Engl J Med Overseas Ed 1996;335:1933-40.

8 Ghanbari H, Dalloul G, Hasan R, et al. Effectiveness of implantable cardioverterdefibrillators for the primary prevention of sudden cardiac death in women with advanced heart failure: a meta-analysis of randomized controlled trials. Arch Intern Med 2009;169:1500-6.

9 Zeitler EP, Hellkamp AS, Schulte PJ, et al. Comparative effectiveness of implantable cardioverter defibrillators for primary prevention in women. Circ Heart Fail 2016:9:e02630

10 Klein L, Grau-Sepulveda MV, Bonow RO, et al. Quality of care and outcomes in women hospitalized for heart failure. Circ Heart Fail 2011;4:589-98. 
11 Larsen PD, De Silva P, Harding SA, et al. Use of implantable cardioverter defibrillators in the New Zealand context from 2000 to 2007. N Z Med J 2010;123:76-85.

12 Statistics New Zealand. District Health Boards Ethnic Group Population Projections, 2014-43 (2013-Base) - 2016 Update. Wellington: Statistics New Zealand, 2016.

13 Rathore SS, Foody JM, Wang Y, et al. Sex, quality of care, and outcomes of elderly patients hospitalized with heart failure: findings from the national heart failure project. Am Heart J 2005; 149:121-8.

14 Nicol ED, Fittall B, Roughton M, et al. NHS heart failure survey: a survey of acute heart failure admissions in England, Wales and Northern Ireland. Heart 2008;94:172-7.

15 Al-Khatib SM, Hellkamp AS, Hernandez AF, et al. Trends in use of implantable cardioverter-defibrillator therapy among patients hospitalized for heart failure: have the previously observed sex and racial disparities changed over time? Circulation 2012;125:1094-101.

16 Hernandez AF, Fonarow GC, Liang L, et al. Sex and racial differences in the use of implantable cardioverter-defibrillators among patients hospitalized with heart failure. JAMA 2007;298:1525-32.

17 Smith W. New Zealand Pacing and Electrophysiology Group. New Zealand primary implantable cardioverter defibrillator implantation and biventricular pacing guidelines. N Z Med J 2010;123:86-96.

18 Heiat A, Gross CP, Krumholz HM. Representation of the elderly, women, and minorities in heart failure clinical trials. Arch Intern Med 2002;162:1682-8.

19 Russo AM, Daugherty SL, Masoudi FA, et al. Gender and outcomes after primary prevention implantable cardioverter-defibrillator implantation: findings from the National Cardiovascular Data Registry (NCDR). Am Heart J 2015;170:330-8.

20 MacFadden DR, Crystal E, Krahn AD, et al. Sex differences in implantable cardioverterdefibrillator outcomes: findings from a prospective defibrillator database. Ann Intern Med 2012;156:195-203.

21 Providência R, Marijon E, Lambiase PD, et al. Primary prevention implantable cardioverter defibrillator (icd) therapy in women-data from a multicenter french registry. J Am Heart Assoc 2016;5.
22 Seegers J, Conen D, Jung K, et al. Sex difference in appropriate shocks but not mortality during long-term follow-up in patients with implantable cardioverterdefibrillators. Europace 2016;18:1194-202.

23 Conen D, Arendacká B, Röver C, et al. Gender differences in appropriate shocks and mortality among patients with primary prophylactic implantable cardioverterdefibrillators: systematic review and meta-analysis. PLoS One 2016;11:e0162756.

24 Moss AJ, Schuger C, Beck CA, et al. Reduction in inappropriate therapy and mortality through ICD programming. N Eng/ J Med 2012;367:2275-83.

25 Gasparini M, Proclemer A, Klersy C, et al. Effect of long-detection interval vs standarddetection interval for implantable cardioverter-defibrillators on antitachycardia pacing and shock delivery: the ADVANCE III randomized clinical trial. JAMA 2013;309:1903-11.

26 Saeed M, Hanna I, Robotis D, et al. Programming implantable cardioverterdefibrillators in patients with primary prevention indication to prolong time to first shock: results from the provide study. J Cardiovasc Electrophysiol 2014;25:52-9.

27 Wilkoff BL, Fauchier L, Stiles MK, et al. 2015 HRS/EHRA/APHRS/SOLAECE expert consensus statement on optimal implantable cardioverter-defibrillator programming and testing. J Arrhythm 2016;32:1-28.

28 Wasywich CA, Gamble GD, Whalley GA, et al. Understanding changing patterns of survival and hospitalization for heart failure over two decades in New Zealand: utility of 'days alive and out of hospital' from epidemiological data. Eur J Heart Fail 2010;12:462-8

29 Kosiborod M, Lichtman JH, Heidenreich PA, et al. National trends in outcomes among elderly patients with heart failure. Am J Med 2006;119:616.e1-616.e7.

30 Zusterzeel R, Selzman KA, Sanders WE, et al. Cardiac resynchronization therapy in women: US food and drug administration meta-analysis of patient-level data. JAMA Intern Med 2014;174:1340-8. 